ASTHMA

\title{
Clinical and atopic parameters and airway inflammatory markers in childhood asthma: a factor analysis
}

\author{
T F Leung, G W K Wong, F W S Ko, C W K Lam, T F Fok
}

See end of article for authors' affiliations

....................

Correspondence to: Dr T F Leung, Department of Paediatrics, 6/F, Clinical Sciences Building Prince of Wales Hospital, Shatin, NT, Hong Kong SAR, China; ffleung@cuhk. edu.hk

Received

15 December 2004

Accepted 30 June 2005

Published Online First

29 July 2005
Background: Recent studies have repeatedly shown weak correlations among lung function parameters, atopy, exhaled nitric oxide level (FeNO), and airway inflammatory markers, suggesting that they are nonoverlapping characteristics of asthma in adults. A study was undertaken to determine, using factor analysis, whether the above features represent separate dimensions of childhood asthma.

Methods: Clinically stable asthmatic patients aged 7-18 years underwent spirometric testing, methacholine bronchial challenge, blood sampling for atopy markers and chemokine levels (macrophage derived chemokine (MDC), thymus and activation regulated chemokine (TARC), and eotaxin), FeNO, and chemokines (MDC and eotaxin) and leukotriene $\mathrm{B}_{4}$ measurements in exhaled breath condensate (EBC). Results: The mean (SD) forced expiratory volume in 1 second $\left(\mathrm{FEV}_{1}\right)$ and FeNO of 92 patients were 92.1 (15.9)\% predicted and 87.3 (65.7) ppb, respectively. 59\% of patients received inhaled corticosteroids. Factor analysis selected four different factors, explaining 55.5\% of total variance. The Kaiser-Meyer-Olkin measure of sampling adequacy was 0.587 . Plasma total and specific lgE levels, peripheral blood eosinophil percentage, and FeNO loaded on factor 1; plasma TARC and MDC concentrations on factor 2; $M D C$, eotaxin and leukotriene $B_{4}$ concentrations in $E B C$ on factor 3 ; and plasma eotaxin concentration together with clinical indices including body mass index and disease severity score loaded on factor 4 . Post hoc factor analyses revealed similar results when outliers were excluded.

Conclusions: The results suggest that atopy related indices and airway inflammation are separate dimensions in the assessment of childhood asthma, and inflammatory markers in peripheral blood and $\mathrm{EBC}$ are non-overlapping factors of asthma.
A sthma is characterised by reversible airway obstruction, bronchial hyperresponsiveness (BHR), and atopy. ${ }^{1} \mathrm{~A}$ number of clinical and spirometric parameters are used to evaluate the severity of the disease and to assess the response to treatment in chronic stable asthma. ${ }^{2}$ Traditionally, clinical symptomatology and disease scores as well as physiological measures of airway function (spirometry, peak expiratory flow rate, bronchial provocation) have been the primary means of assessing asthmatic patients. There has been increasing interest in monitoring airway inflammation in asthma. The cellular inflammatory response of the bronchial mucosa in asthma is characterised by eosinophil infiltration. Sputum eosinophilia is also shown to reflect disease severity of asthma. ${ }^{3-5}$ We recently reported that type $2 \mathrm{~T}$ helper lymphocyte (Th2) specific chemokines were associated with eosinophilia in peripheral blood and were increased in acute and chronic stable asthma. ${ }^{6-8}$ These patients also had increased nitric oxide (NO) and inflammatory mediators in exhaled breath. ${ }^{9-11}$ In many studies, however, there were poor interrelations between these outcome measures. ${ }^{5}$ 10-13 For instance, the concentrations of Th2 specific chemokines (thymus and activation regulated chemokine (TARC), macrophage derived chemokine (MDC) and eotaxin) in exhaled breath condensate (EBC) did not show good correlations with those measured in peripheral blood in asthmatic children. ${ }^{10}$ The clinical, atopic, and inflammatory variables might therefore provide complementary data for monitoring the disease.

Factor analysis is commonly used to reduce a large number of disease parameters to a relatively small number of independent "factors". As each factor groups associated parameters, the results help to provide insight into the pathogenesis of complex diseases. Being essentially free of a predetermined hypothesis on any interrelated parameters, this statistical technique can be viewed as a hypothesis generating tool. Factor analysis has been applied previously in studies of asthma in adults, ${ }^{14-17}$ and the results showed that clinical characteristics, spirometric parameters, BHR, and sputum inflammatory markers are non-overlapping dimensions. Assessment of disease control and severity in adults with asthma should therefore include measurements of all these parameters. Relevant data on factor analysis in childhood asthma are limited. ${ }^{18}{ }^{19}$ Furthermore, most of the previous studies did not include atopic factors (such as plasma total and specific IgE levels) and emerging biomarkers of airway inflammation (such as NO and other mediators in exhaled air). The aim of this study was to specify objectively the heterogeneity of childhood asthma by categorising a number of functional, atopic, and inflammatory features of chronic stable asthma into separate complementary domains without a priori assumption. Such statistical evidence would further support the utility of routine measurement of all these dimensions.

\section{METHODS}

\section{Study population}

Patients aged 7-18 years with clinically stable asthma, diagnosed according to American Thoracic Society guideline, ${ }^{1}$

\footnotetext{
Abbreviations: BHR, bronchial hyperresponsiveness; BMI, body mass index; $E B C$, exhaled breath condensate; FENO, exhaled nitric oxide; $\mathrm{FEV}_{1}$, forced expiratory volume in 1 second; FVC, forced vital capacity; MDC, macrophage derived chemokine; NO, nitric oxide; TARC, thymus and activation regulated chemokine
} 
were recruited from the paediatric outpatient clinic of a university teaching hospital in Hong Kong. None were cigarette smokers. The patients had been free from symptoms of infection for 2 weeks before the study. Their anti-asthma treatments were also stabilised for at least 3 months. Asthma severity in these subjects was assessed by the disease severity score (DSS), ${ }^{20}$ a composite score that included daytime, night time and exercise induced symptoms, frequency of asthmatic exacerbation, and the use of anti-asthma medications, as well as by the Global Initiative for Asthma (GINA) criteria. ${ }^{2}$ Body weight and height were measured with the subject lightly clothed and barefooted using an electronic weighing scale (Model 708, Seca, Germany) and Harpenden stadiometer.

The parents of the subjects gave written informed consent and the Clinical Research Ethics Committee of our university approved the study.

\section{Pulmonary function testing}

All patients underwent spirometric assessment (Compact II, Vitalograph, Buckingham, UK) to measure their forced expiratory volume in 1 second $\left(\mathrm{FEV}_{1}\right)$ and forced vital capacity (FVC) which were compared with the local reference values. ${ }^{21}$ BHR was tested by inhalation of methacholine according to the protocol reported by Yan et al..$^{22} \mathrm{PD}_{20}$ (the provocative dose of methacholine that resulted in a $20 \%$ fall in $\mathrm{FEV}_{1}$ ) was noted from the log dose-response curve.

\section{Exhaled NO measurement}

The fractional exhaled NO concentration (FeNO) was measured at an expiratory flow rate of $50 \mathrm{ml} / \mathrm{s}$ using a chemiluminescence analyser (NOA280i, Sievers Instruments, Boulder, CO, USA) according to ERS/ATS standard. ${ }^{23}$ Repeated exhalations were performed without nose clip until three NO plateau values agreed at the $10 \%$ level. The mean Feno value was then recorded.

\section{Measurement of atopy and plasma inflammatory markers}

Eosinophils in EDTA anticoagulated venous blood were counted using a Coulter STKS counter (Beckman-Coulter, Miami, FL, USA). The plasma total IgE concentration was measured by microparticle immunoassay (IMx analyser, Abbott Laboratories, Abbott Park, IL, USA), and specific IgE to Dermatophagoides pteronyssinus (the most prevalent local aeroallergen $)^{8}$ was measured by fluorescent enzyme immunoassay (AutoCAP analyser, Pharmacia Diagnostics AB, Uppsala, Sweden). Patients with D pteronyssinus specific IgE (levels $\geqslant 0.35 \mathrm{kU} / \mathrm{l}$ ) were considered atopic. Plasma concentrations of TARC, MDC, and eotaxin were measured in duplicates by sandwich enzyme immunoassays (MDC and TARC: R \& D Systems, Minneapolis, MN, USA; eotaxin: Biosource International, Camarillo, CA, USA). The detection limits of these chemokines were 7, 62.5 and $2.2 \mathrm{pg} / \mathrm{ml}$, respectively.

\section{Measurement of chemokines and $\mathrm{LTB}_{4}$ in breath condensate}

Following mouth rinse, the subjects breathed tidally into the disposable RTube (Respiratory Research, Charlottesville, VA, USA) for 10 minutes. ${ }^{10}{ }^{11} \mathrm{EBC}$ thus obtained was immediately stored at $-70^{\circ} \mathrm{C}$ until being assayed for MDC and eotaxin in one batch using the commercial kits described above. The concentration of leukotriene $\mathrm{B}_{4}\left(\mathrm{LTB}_{4}\right)$ was also measured by acetylcholinesterase competitive enzyme immunoassay (Cayman Chemical, Ann Arbor, MI, USA). The detection limit of this assay for $\mathrm{LTB}_{4}$ was $4 \mathrm{pg} / \mathrm{ml}$.

\section{Statistical analysis}

The results were expressed as proportions, mean and standard deviation (SD), or median and interquartile range (IQR). Variables with non-Guassian distribution were logarithmically transformed before analysis. Exploratory factor analysis included the following 12 variables: clinical (body mass index (BMI), DSS); atopic (total and D pteronyssinus specific IgE, peripheral blood eosinophils), and inflammatory markers in peripheral blood (TARC, MDC and eotaxin) and EBC (Feno, MDC, eotaxin, $\mathrm{LTB}_{4}$ ). Because only 68 patients could successfully perform lung function measurements $\left(\mathrm{FEV}_{1}, \mathrm{FVC}, \mathrm{FEV}_{1} / \mathrm{FVC}\right.$ and $\mathrm{PD}_{20}$; table 1$)$, these spirometric parameters were not included in the factor analysis in order to maintain an acceptable ratio between sample size and number of variables included. ${ }^{24}$ Bartlett's test of sphericity was used to test for the possibility to perform factor analysis. The Kaiser-Meyer-Olkin (KMO) measure of sampling adequacy was also evaluated. A high KMO (maximum 1.0; minimum acceptable 0.5 ) indicates that data are likely to factor well since correlations between pairs of variables can be explained by the other variables (low partial correlation coefficients).

Correlation coefficients were analysed by principal component analysis and subsequent rotation according to the standard varimax criterion. ${ }^{24} 25$ In this type of analysis the correlation between parameters is attributed to their common dependence on independent entities called "factors". The coefficients that link parameters to factors are called "factor loadings"; the number of factors is chosen to be as small as possible but large enough to account for most of the variation within the data. It was decided a priori that the number of factors in the varimax rotation would be based on the number of eigenvalues $\geqslant 1.0$ in the principal component analysis. ${ }^{26}$ To assess the robustness of our findings we repeated the factor analysis after excluding outliers from the data set (defined as data outside the range of mean $\pm 3 S D)$ to determine the stability of the factor structures. Because no procedure is known for estimating standard errors of factor loadings, this study did not evaluate any statistical significance. Instead, we adopted one common and conventional rule of thumb to consider "factor loadings" of 0.45 or larger to be "high". ${ }^{24}$

All analyses were performed with the Statistical Package of Social Sciences for Windows version 10.1 (SPSS Inc, Chicago, IL, USA).

\section{RESULTS \\ Subjects}

Ninety two consecutive asthmatic children were approached and all consented to participate. Table l summarises their clinical and laboratory characteristics. Forty five (49\%) were receiving inhaled corticosteroid (ICS) treatment and nine were receiving treatment with a combination of ICS and inhaled long acting $\beta$ agonist. Eighty eight patients (96\%) were atopic. BHR was present in $26(68 \%)$ steroid naive and $21(70 \%)$ ICS treated patients, respectively $(p=0.889)$.

\section{Asthma severity and study parameters}

According to the GINA criteria, 31 patients (34\%) suffered from intermittent asthma, $34(37 \%)$ from mild persistent asthma, $12(13 \%)$ from moderate persistent asthma, and 15 (16\%) from severe persistent asthma. Plasma TARC and MDC concentrations were significantly higher in patients with persistent asthma than in those with intermittent disease $(p=0.006$ and $p=0.009$, respectively, ANOVA; fig 1$)$. Other measured clinical, atopic, spirometric, or inflammatory parameters did not differ among the various GINA groups (results not shown). 
Table 1 Characteristics of study patients

\begin{tabular}{|c|c|c|c|}
\hline & $\mathbf{N}$ & Value $^{*}$ & Reference range $q$ \\
\hline \multicolumn{4}{|l|}{ Clinical characteristics } \\
\hline Age (years) & 92 & $12.7(3.4)$ & NA \\
\hline Male gender, $\mathrm{n}(\%)$ & 92 & $64(70)$ & NA \\
\hline Body mass index $\left(\mathrm{kg} / \mathrm{m}^{2}\right)$ & 92 & $19.0(3.5)$ & NA \\
\hline Disease severity score (range 6-30) & 92 & $11(9-14)$ & NA \\
\hline \multicolumn{4}{|l|}{ Atopic features } \\
\hline Plasma total lgE concentration (kU/l) & 92 & $611(271-1256)$ & $\begin{array}{l}\leqslant 160 \text { for } 7 \text { years; } \\
\leqslant 180 \text { for } \geqslant 8 \text { years }\end{array}$ \\
\hline Specific lgE to D pteronyssinus (kU/l) & 92 & 105 (39-145) & $<0.35$ \\
\hline Peripheral blood eosinophil (\%) & 92 & $8(5-10)$ & $\leqslant 3$ \\
\hline Absolute eosinophil count $\left(10^{9} / \mathrm{l}\right)$ & 92 & $0.52(0.35-0.77)$ & $\leqslant 0.25$ \\
\hline \multicolumn{4}{|l|}{ Lung function† } \\
\hline $\mathrm{FEV}_{1}$ predicted (\%) & 80 & $92.1(15.9)$ & $\geqslant 80$ \\
\hline FVC predicted (\%) & 80 & $104.8(17.3)$ & $\geqslant 80$ \\
\hline $\mathrm{FEV}_{1} / \mathrm{FVC}(\%)$ & 80 & $80.0(9.6)$ & $\geqslant 80$ \\
\hline $\mathrm{PD}_{20}(\mu \mathrm{mol})$ & 68 & $1.95(0.58-6.00)$ & $>7.8$ \\
\hline \multicolumn{4}{|l|}{ Inflammatory markersł } \\
\hline FeNO (ppb) & 92 & $72.4(39.5-117.8)$ & $\leqslant 30$ \\
\hline Plasma TARC concentration $(\mathrm{pg} / \mathrm{ml})$ & 92 & $45.0(26.8-85.3)$ & $\leqslant 70$ \\
\hline Plasma MDC concentration (pg/ml) & 92 & $540(411-702)$ & $\leqslant 480$ \\
\hline Plasma eotaxin concentration $(\mathrm{pg} / \mathrm{ml})$ & 92 & $39.0(33.5-47.5)$ & $\leqslant 45$ \\
\hline EBC MDC concentration $(\mathrm{pg} / \mathrm{ml})$ & 92 & $113(93-126)$ & $\leqslant 105$ \\
\hline EBC eotaxin concentration $(\mathrm{pg} / \mathrm{ml})$ & 92 & $37.0(33.0-43.3)$ & $\leqslant 35$ \\
\hline EBC $\mathrm{LTB}_{4}$ concentration $(\mathrm{pg} / \mathrm{ml})$ & 92 & $39.9(31.4-47.7)$ & $\leqslant 35$ \\
\hline \multicolumn{4}{|c|}{ 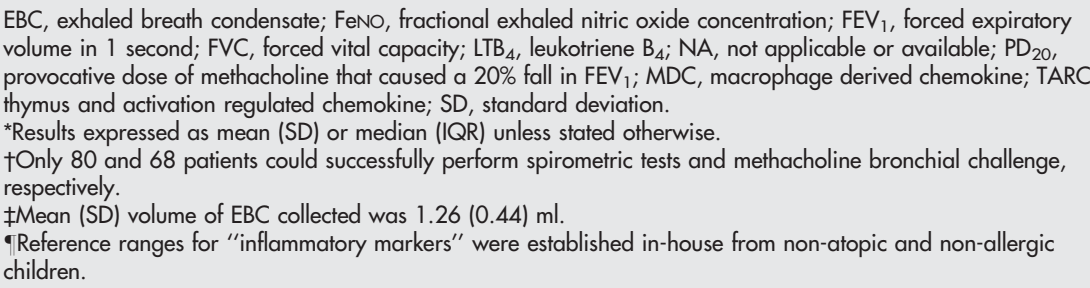 } \\
\hline
\end{tabular}
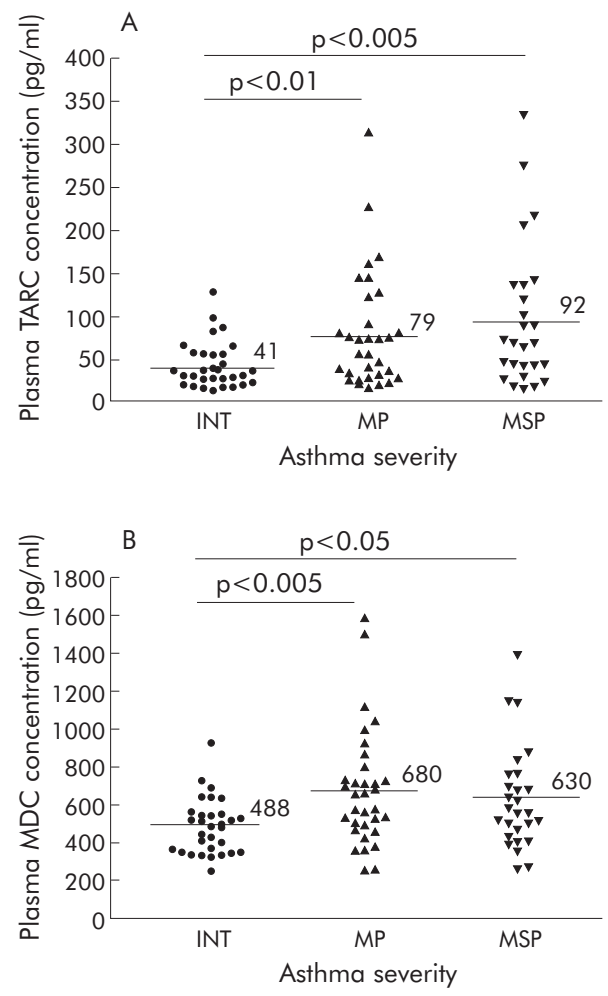

Figure 1 Distribution of plasma concentrations of $(A)$ thymus and activation regulated chemokine (TARC) and (B) macrophage derived chemokine (MDC) in asthmatic patients with intermittent (INT), mild persistent (MP), and moderate to severe persistent (MSP) disease. Horizontal bars indicate the mean values for the respective groups.

\section{Factor analysis}

Bartlett's test of sphericity indicated a correlation between the presently used variables because the correlation matrix was statistically different from an identity matrix $\left(\chi^{2}=135.8\right.$, degree of freedom $=66, p<0.0001)$. The KMO measure of sampling adequacy was 0.587 . Factor analysis yielded four separate factors that could explain $55.5 \%$ of the total variance in the data set when the "eigenvalue $=1$ " criterion was used. The addition of one more factor only resulted in an increase in the total explained variance to $63.8 \%$. Thus, factor analysis with four components was presented (table 2). When factor analysis was repeated after excluding outliers $>3 \mathrm{SD}$, the KMO measure of sampling adequacy was 0.580 . A total of five factors were identified (table 3 ). The robustness of the original factor structure was confirmed by the fact that all parameters except those in the original factor 4 (DSS, BMI, and plasma eotaxin concentration) were clustered into the same factors when outliers were excluded. Plasma eotaxin interestingly "returned" to the same factor as plasma TARC and MDC concentrations, and DSS and BMI were separated into two independent factors.

\section{DISCUSSION}

This study focused on the factor analysis of asthma related parameters in 92 children and adolescents with chronic stable asthma. Most of these patients had normal or mildly obstructed airways (mean $\mathrm{FEV}_{1}$ 92\%) but with significant airway inflammation (mean Feno 87.3 ppb). Factor analysis reduced 12 parameters into mostly four different factors with satisfactory sampling adequacy. Plasma total and $D$ pteronyssinus specific IgE levels, peripheral blood eosinophil percentage, and Feno loaded on factor 1, plasma Th2 specific chemokines (TARC and MDC) loaded on factor 2, MDC, eotaxin and $\mathrm{LTB}_{4}$ levels in EBC loaded on factor 3, and DSS, BMI, and plasma eotaxin level loaded on factor 4. Post hoc 
Table 2 Varimax rotated factor loading matrix for all 92 asthmatic patients

\begin{tabular}{|c|c|c|c|c|}
\hline & Factor 1 & Factor 2 & Factor 3 & Factor 4 \\
\hline Plasma total lgE concentration & 0.710 & 0.034 & -0.009 & -0.270 \\
\hline Specific lgE to $D$ pteronyssinus & 0.684 & 0.031 & -0.016 & -0.020 \\
\hline Peripheral blood eosinophil percentage & 0.609 & 0.158 & -0.037 & 0.147 \\
\hline FeNO & 0.576 & -0.392 & -0.215 & 0.408 \\
\hline Plasma TARC concentration & 0.088 & 0.839 & -0.020 & 0.222 \\
\hline Plasma MDC concentration & 0.089 & 0.795 & -0.183 & -0.187 \\
\hline EBC $\mathrm{LTB}_{4}$ concentration & -0.141 & -0.100 & 0.726 & 0.199 \\
\hline EBC MDC concentration & -0.295 & 0.007 & 0.628 & 0.037 \\
\hline $\mathrm{EBC}$ eotaxin concentration & -0.301 & -0.130 & 0.590 & 0.018 \\
\hline Disease severity score & 0.014 & 0.097 & 0.217 & 0.681 \\
\hline Body mass index & -0.025 & -0.073 & 0.037 & 0.579 \\
\hline Plasma eotaxin concentration & -0.009 & 0.461 & -0.341 & 0.550 \\
\hline Eigenvalue & 1.89 & 1.77 & 1.52 & 1.49 \\
\hline Total variance explained (\%) & 15.7 & 14.8 & 12.6 & 12.4 \\
\hline
\end{tabular}

factor analyses revealed similar clustering of the parameters when outliers were excluded.

This is the first study using factor analyses to show that the inflammatory markers (MDC and eotaxin) being measured in both peripheral blood and EBC are assigned to separate factors. Although the results from this limited study should not be generalisable to other biomarkers, our findings support the possibility that inflammatory mediators may be differentially regulated in these compartments in childhood asthma.

The factor analysis clearly demonstrated weak correlations between clinical, atopic and inflammatory parameters in childhood asthma. These differences can probably be explained by the fact that the health status of asthma has a number of distinct components. If the poor correlations are due mainly to measurement error of a single concept, the asthma parameters will not be separated into such clinically sensitive dimensions. BMI, plasma IgE levels, and airway inflammatory markers were consistently segregated into different components. In addition, although it was specified a priori that the number of factors in the varimax rotation would be based on the number of eigenvalues $\geqslant 1.0$ in the principal component analysis, exploratory rotations with both three and five factors were also conducted. The distributions on these alternative numbers of factors did not significantly alter the total variance explained. Lastly, all

Table 3 Distribution of parameters into different factors after exclusion of outliers

\begin{tabular}{|c|c|c|}
\hline & With outliers & No outliers* \\
\hline $\begin{array}{l}\text { Plasma total lgE concentration } \\
\text { Specific lgE to } D \text { pteronyssinus } \\
\text { Peripheral blood eosinophil percentage } \\
\text { FeNO } \\
\text { Plasma TARC concentration } \\
\text { Plasma MDC concentration } \\
\text { EBC LTB }{ }_{4} \text { concentration } \\
\text { EBC MDC concentration } \\
\text { EBC eotaxin concentration } \\
\text { Disease severity score } \\
\text { Body mass index } \\
\text { Plasma eotaxin concentration } \\
\text { Total variance explained }\end{array}$ & $\begin{array}{l}\text { Factor } 1 \\
\text { Factor } 1 \\
\text { Factor } 1 \\
\text { Factor } 1 \\
\text { Factor } 2 \\
\text { Factor } 2 \\
\text { Factor } 3 \\
\text { Factor } 3 \\
\text { Factor } 3 \\
\text { Factor } 4 \\
\text { Factor } 4 \\
\text { Factor } 4 \\
55.5 \%\end{array}$ & $\begin{array}{l}\text { Factor } 1 \\
\text { Factor } 1 \\
\text { Factor } 1 \\
\text { Factor } 1 \\
\text { Factor } 2 \\
\text { Factor } 2 \\
\text { Factor } 3 \\
\text { Factor } 3 \\
\text { Factor } 3 \\
\text { Factor } 4 \\
\text { Factor } 5 \\
\text { Factor } 2 \\
64.6 \%\end{array}$ \\
\hline
\end{tabular}

EBC, exhaled breath condensate; $\mathrm{LTB}_{4}$, leukotriene $\mathrm{B}_{4} ; \mathrm{MDC}$, macrophage derived chemokine; TARC, thymus and activation regulated chemokine; FENO, exhaled nitric oxide.

*Five factors were obtained after the exclusion of all outliers, with the respective eigenvalues being $1.92,1.75,1.55,1.30$, and 1.23 and the percentage of total variances explained being $16.0 \%, 14.6 \%, 12.9 \%$, $10.9 \%$, and $10.2 \%$. "factor loadings" were larger than 0.45 (table 2) and our final model explained more than $50 \%$ of the total variance. ${ }^{24}$ These results suggest a good assignment of the variables into the four factors.

Factor analysis reduces a large number of related or even seemingly unrelated parameters into a relatively small number of "factors". As this method does not require a predetermined hypothesis on any interrelated parameters, this statistical technique is invaluable for determining possible ways to categorise the many dimensions of complex diseases such as asthma. However,, this approach does not offer any mechanistic link between variables that cluster in the same factor. In addition, the clustering of variables obtained may apparently be unexplained from the clinical point of view. We should therefore be very careful in deciding on the optimal number of factors (with the help of Scree plot, eigenvalues, etc) while making the best biological sense of the results. ${ }^{24-26}$

Factor analysis has not been widely applied in studying asthma related parameters in children. Among Chinese children, Qian and colleagues conducted factor analysis to examine the associations between respiratory health outcomes and household risk factors. ${ }^{18}$ They found that the five factors of heating coal smoke, socioeconomic status, ventilation, environmental tobacco smoke, and parental asthma were independently associated with asthma. In another study on asthmatic children, principal components and factor analysis suggested two independent factors-atopy related indices and loci on chromosome 5q31-33 that encoded the cytokine gene cluster. ${ }^{19}$ The present study provides further data to this expanding field by suggesting different nonoverlapping clinical, atopic, and inflammatory factors in childhood asthma.

Clinical measures of asthma were shown to have poor correlations with subjective quality of life indicators, ${ }^{17}$ and the occurrence of asthma symptoms was also independent of subjects' BMI and measures of airway function. ${ }^{27}$ These observations open up a new dimension for clinical trials; any new asthma treatment should aim to reduce asthma specific mortality and morbidity and improve patient well being, daily activities, and emotional stability. ${ }^{28}$ In asthma the conventional clinical outcomes address the first concern and quality of life assessment addresses the latter. Thus, subjective patient status has to be measured and interpreted independently. To complicate the issue, the present study suggests that airway inflammatory markers in peripheral blood and EBC are different dimensions in the assessment of childhood asthma. It will be interesting and important to know the ways in which different asthma interventions bring about 
improvements in clinical, immunological, and quality of life outcomes in these patients.

This study included BMI in the factor analysis because of a number of recent publications on an epidemiological association between asthma and obesity. ${ }^{27}{ }^{29-31}$ This relation seemed to be present, irrespective of atopy and eosinophil counts. ${ }^{27} 31$ In the Childhood Asthma Management Program, BMI was independently associated with $\mathrm{FEV}_{1}, \mathrm{FVC}$, and $\mathrm{FEV}_{\mathrm{l}} / \mathrm{FVC}$ but not with asthma symptoms or atopy. ${ }^{27}$ Our recent study also could not find any association between BMI and spirometric variables, percentage of peripheral blood eosinophils, FenO, or LTB $_{4}$ levels in EBC. ${ }^{11}$ Whereas the mechanical properties of the respiratory system associated with obesity may account for this linkage, obese patients were found to have increased levels of leptin and pro-inflammatory cytokines. ${ }^{32}$ These pathways may be independent of Th2 specific chemokines, so our factor analyses failed to reveal any correlation between BMI and inflammatory markers in peripheral blood or EBC.

Although 12 asthma related parameters are grouped into four factors in this study, this does not mean that childhood asthma is determined only by four factors. There may be other factors that are not captured by these 12 items. For example, quality of life has been found to be an important component of asthma ${ }^{17}$ but this was not measured in our patients. Although it is too invasive to use bronchial biopsy samples to monitor asthma, the presence of inflammatory markers (such as eosinophils and chemical mediators) in induced sputum has not been evaluated. The inflammatory markers included in this study may also be associated with other as yet unidentified factors. Additional studies should be performed to examine the mechanisms that link the four components of childhood asthma identified in this study.

In conclusion, this study suggests that asthma related parameters including atopic factors and airway inflammatory markers are non-overlapping dimensions in the assessment of chronic stable asthma in children. Specifically, inflammatory markers in peripheral blood and EBC should be considered as separate dimensions. The results support the usefulness of routine measurement of these dimensions in monitoring childhood asthma.

\section{ACKNOWLEDGEMENTS}

The authors thank I H S Chan for measuring total and allergen specific IgE and C Y Li, E Yung, C S S Au, and E K H Liu for measuring Feno and inflammatory markers in peripheral blood and EBC.

\section{Authors' affiliations}

T F Leung, G W K Wong, T F Fok, Department of Paediatrics, The Chinese University of Hong Kong, Prince of Wales Hospital, Hong Kong SAR, China

F W S Ko, Department of Medicine and Therapeutics, The Chinese University of Hong Kong, Prince of Wales Hospital, Hong Kong SAR, China

C W K Lam, Department of Chemical Pathology, The Chinese University of Hong Kong, Prince of Wales Hospital, Hong Kong SAR, China

This research project is funded by Hong Kong Research Grant Council Earmarked Grant (CUHK 4165/O2M) and Direct Grant for Research of The Chinese University of Hong Kong.

Competing interests: none of the authors of this article has any competing interest.

\section{REFERENCES}

1 American Thoracic Society. Standards for the diagnosis and care of patients with chronic obstructive pulmonary disease (COPD) and asthma. Am Rev Respir Dis 1987; 136:225-44.
2 Global Initiative for Asthma. Global strategy for asthma management and prevention, NIH Publication No 02-3659. Bethesda, MD: NHLBI, 2004.

3 Bousquet J, Chanez P, Lacoste JY, et al. Eosinophilic inflammation in asthma. N Engl J Med 1990;323:1033-9.

4 Ollerenshaw SL, Woolcock AJ. Characteristics of the inflammation in biopsies from large airways of subjects with asthma and subjects with chronic airway limitation. Am Rev Respir Dis 1992;145:922-7.

5 Ronchi MC, Piragino C, Rosi E, et al. Do sputum eosinophils and ECP relate to the severity of asthma? Eur Respir J 1997; 10:1809-13.

6 Leung TF, Wong CK, Chan IH, et al. Plasma concentration of thymus and activation-regulated chemokine is elevated in childhood asthma. J Allergy Clin Immunol 2002;1 10:404-9.

7 leung TF, Wong CK, Lam CW, et al. Plasma TARC concentration may be a useful marker for asthmatic exacerbation in children. Eur Respir $J$ 2003;21:616-20.

8 Leung TF, Tang NL, Li CY, et al. Association between TARC C-431T and atopy and asthma in children. J Allergy Clin Immunol 2004;1 14:199-202.

9 Kharitonov SA, Yates D, Robbins RA, et al. Increased nitric oxide in exhaled air of asthmatic patients. Lancet 1994;343:133-5.

10 leung TF, Wong GW, Ko FW, et al. Increased macrophage-derived chemokine in exhaled breath condensate and plasma from children with asthma. Clin Exp Allergy 2004;34:786-91.

11 Leung TF, Li CY, Lam CWK, et al. The relation between obesity and asthmatic airway inflammation. Pediatr Allergy Immunol 2004;15:344-50.

12 Crimi E, Spanevello A, Neri M, et al. Dissociation between airway inflammation and airway hyperresponsiveness in allergic asthma. Am J Respir Crit Care Med 1998;157:4-9.

13 Ronchi MC, Piragino C, Rosi E, et al. Role of sputum differential count in detecting airway inflammation in patients with chronic bronchial asthma. Thorax 1996;51:1-5.

14 Rosi E, Ronchi MC, Grazzini M, et al. Sputum analysis, bronchial hyperresponsiveness, and airway function in asthma: results of a factor analysis. J Allergy Clin Immunol 1999;103:232-7

15 Ottanelli R, Rosi E, Romagnoli I, et al. Do inhaled corticosteroids affect perception of dyspnea during bronchoconstriction in asthma? Chest 2001;120:770-7

16 Gronke L, Kanniess F, Holz O, et al. The relationship between airway hyperresponsiveness, markers of inflammation and lung function depends on the duration of the asthmatic disease. Clin Exp Allergy 2002;32:57-63.

17 Juniper EF, Wisniewski ME, Cox FM, et al. Relationship between quality of life and clinical status in asthma: a factor analysis. Eur Respir J 2004;23:287-91.

18 Qian Z, Zhang J, Korn LR, et al. Factor analysis of household factors: are they associated with respiratory conditions in Chinese children? Int J Epidemiol 2004;33:582-8.

19 Holberg CJ, Halonen M, Solomon S, et al. Factor analysis of asthma and atopy traits shows two major components, one of which is linked to markers on chromosome 5q. J Allergy Clin Immunol 2001;108:772-80.

20 Brooks SM, Berstein L, Raghuprasad PK, et al. Assessment of airway hyperresponsiveness in chronic stable asthma. J Allergy Clin Immunol 1990;85:17-26.

21 Ip MS, Karlberg EM, Karlberg JP, et al. Lung function reference values in Chinese children and adolescents in Hong Kong. I. Spirometric values and comparison with other populations. Am J Respir Crit Care Med 2000; 162:424-9

22 Yan K, Salome C, Woolcock AJ. Rapid method for measurement of bronchial responsiveness. Thorax 1983;38:760-5.

23 Baraldi E, de Jongste JC, on behalf of the ERS/ATS Task Force. Measurement of exhaled nitric oxide in children. Eur Respir J 2002;20:223-37.

24 Multivariate methods. In: Armitage P, Berry G, Matthews JN, eds. Statistical methods in medical research. Oxford, UK: Blackwell Science, 2002:455-84.

25 Stevens J. Exploratory and confirmatory factor analysis. In: Stevens J, eds. Applied multivariate statistics for the social sciences. Mahwah, NJ: Lawrence Erlbaum Associates, 1996:362-428.

26 Cattell RB. The Scree test for the number of factors. Multivariate Behav Res 1966;1:245-76.

27 Tantisira KG, Litonjua AA, Weiss ST, et al. Childhood Asthma Management Program Research Group. Association of body mass with pulmonary function in the Childhood Asthma Management Program (CAMP). Thorax 2003;58:1036-41

28 Guyatt GH, Naylor D, Juniper EF, et al. Users' guides to the medical literature. IX. How to use an article about health-related quality of life. JAMA 1997;277:1232-7.

29 Luder E, Melnik TA, Dimaio M. Association of being overweight with greater asthma symptoms in inner city black and Hispanic children. J Pediatr 1998; 132:699-703.

30 Gold DR, Rotnitzky A, Damokosh Al, et al. Race and gender differences in respiratory illness and prevalence and their relationship to environmental exposures in children 7 to 14 years of age. Am Rev Respir Dis 1993; 148:10-8.

31 von Mutius E, Schwartz J, Neas LM, et al. Relation of body mass index to asthma and atopy in children: the National Health and Nutrition Examination Study III. Thorax 2001;56:835-8.

32 Visser M, Bouter LM, McQuillan GM, et al. Elevated C-reactive protein levels in overweight and obese adults. JAMA 1999;282:2131-5. 